\title{
Adolescents Traveling to High-Risk Destinations: Review and Considerations for Clinicians
}

\author{
Helena C. Maltezou ${ }^{1 *}$, Androula Pavli ${ }^{1}$ \\ ${ }^{1}$ Department for Interventions in Health Care Facilities, Hellenic Centre for Disease Control and Prevention, Athens, \\ Greece \\ Corresponding Author: Helena C. Maltezou, MD, Department for Interventions in Health Care Facilities, Hellenic \\ Centre for Disease Control and Prevention, 3-5 Agrafon Street, Athens, 15123 Greece. Tel: 30-210-5212-175, Fax: \\ 30-210-5212-177, Email: helen-maltezou@ath.forthnet.gr
}

Received March 27, 2018; Accepted May 13, 2018; Online Published October 18, 2018

\begin{abstract}
Introduction: International travels have increased dramatically in recent years. Adolescents constitute a fast-growing group of travelers. Travels provide an opportunity for exposure to high-risk behavior. The current study reviewed the published data about travel-related morbidity among adolescents traveling to international destinations.

Methods: PubMed was searched for articles published from 2000-2017. The websites of public health organizations were also searched. Results: In total, 21 articles presenting original data about adolescent international travelers were identified. The data indicated that adolescents frequently develop ailments during travel, including those attributable to age-related high-risk behavior. In addition, adolescents often manifest a travel-associated morbidity that differs in terms of proportion (e.g., higher rates of systemic febrile illness) from the travelassociated morbidity encountered in younger children and adults. Pre-travel counseling is sought by less than half of adolescents traveling to high-risk destinations. Gaps were found in travel vaccinations and antimalarial prophylaxis in adolescents traveling to endemic areas. Information about vaccinations, antimalarial prophylaxis, and pre-travel counseling for adolescent travelers should be improved.

Conclusion: There is a need to improve pre-travel services for adolescents planning to travel to high-risk international destinations. Communication strategies to access adolescent travelers and their parents should be investigated.

Keywords: Adolescent, Travel, Malaria, Risk Behavior, Prophylaxis
\end{abstract}

Citation: Maltezou HC, Pavli A. Adolescents traveling to high-risk destinations: review and considerations for clinicians. Int J Travel Med Glob Health. 2018;6(4):141-148. doi:10.15171/ijtmgh.2018.26.

\section{Introduction}

International travels have increased dramatically over the past ten years. In accordance with the World Tourism Organization, international tourist arrivals increased by at least $4 \%$ annually over the past six years. In particular, more than 1.2 billion international tourist arrivals were recorded in 2016 alone. ${ }^{1}$ These trends concern children and adolescents as well as adults. In 2014, 2.4 million children and adolescents <18 years of age traveled from the United States to international destinations, ${ }^{2}$ mainly for vacation, but also to visit friends and relatives (VFRs) or to participate in educational/research activities.

Adolescence refers to a transitional developmental age between childhood and adulthood. During this stage, bodily, biological, cognitive, psychological, and societal changes occur. Adolescence is characterized by an increase in independence in association with limited parental surveillance compared to childhood and a trend for risky behavior, including engagement in motor accidents, illicit drug and alcohol use, unprotected sex and multiple sexual partners. Adolescents constitute a fast-growing group of travelers. ${ }^{3}$ They travel with their families, but also as a group, with their friends, or alone. Travel provides an opportunity for exposure to high-risk behavior in the framework of limited or complete absence of parental surveillance.

There are few articles focusing on adolescent international travelers, and to the best of the authors' knowledge, there is no published review on this topic. The available published data showed that adolescents have a different travel-associated morbidity than younger children and adults. A 10-year study from Germany showed that age was a significant determinant of morbidity among 890 children and adolescents returning from the tropics with an infectious disease. ${ }^{4}$ In particular, adolescents developed dengue significantly more often compared with the young pediatric group $(6.6 \%$ compared to $0.3 \%$, respectively). ${ }^{4}$ Another study from the Geosentinel

Copyright (C) 2018 The Author(s). This is an open-access article distributed under the terms of the Creative Commons Attribution License (http:// creativecommons.org/licenses/by/4.0), which permits unrestricted use, distribution, and reproduction in any medium, provided the original work is properly cited. 
Surveillance Network showed that international travelers 1217 years old had a significantly higher proportionate morbidity rate for systemic febrile illness but a lower one for respiratory illnesses or diarrhea following a trip to Asia, sub-Saharan Africa, or Latin America. ${ }^{5}$ In a study from The Netherlands, adolescents 12-18 years old had 3-times increased morbidity compared to their parents following travel to Asia, subSaharan Africa, or Latin America, which was attributed to their limited parental supervision in association with increased risk-seeking behavior among adolescents. ${ }^{6}$ The objective of the current study was to non-systemically review the literature about adolescent international travelers, looking at particular aspects of their travel-associated morbidity and its prevention.

\section{Methods}

PubMed was searched for articles published from 2000 through 2017 using a combination of the words "adolescents", "children", "pediatric", "travelers" and "travelers". A total of 1178 articles were found. After the abstracts were read, 52 articles were selected for a complete reading. Among them, 31 articles were excluded because either there was no data about adolescent travelers or data about adolescent travelers could not be retrieved for analysis. Finally, 21 articles that presented original data about adolescent travelers was included in the study. ${ }^{4-24}$ Review articles were also read, and the websites of public health organizations (World Health Organization [WHO], Center for Disease Control and Prevention [CDC], Public Health England) and the website of the WHO were searched for data about travels. Finally, 47 articles were included in this review based on their relevance to the study topic. Articles were studied by both authors independently. The review was conducted in accordance with the PRISMA statement (Figure 1).

Children, adolescents and adults were defined as persons $<12$ years, $12-18$ years, and $>18$ years of age, respectively. VFR travelers were defined as travelers whose primary purpose was travel to VFRs. ${ }^{25}$

\section{Results and Discussion}

Profile and Level of Preparedness of Adolescent International Travelers

Pre-travel consultation is very important for safe international travel. In this section, the level of pre-travel preparedness of adolescents traveling abroad is discussed. Four studies presenting original data about the preparedness of adolescent international travelers were identified. ${ }^{7,8,12}$ In the first, an airport-based study of 68 adolescents traveling from Greece to high-risk African or Asian destinations, only one third sought pre-travel services. ${ }^{7}$ The second study of 239 adolescents from Greece traveling mainly to sub-Saharan Africa or Latin America for at least 3 months revealed that adolescents more frequently planned to visit rural areas and to engage in adventure sports compared with children and adults. ${ }^{8}$ Both studies found significant gaps in vaccinations against typhoid fever, rabies, Japanese encephalitis, and meningococcus despite traveling to endemic areas; however, in many cases pre-travel services provided a good opportunity to catch-up routine vaccinations in adolescents. ${ }^{7,8}$ Gaps in prescription of anti-malarial prophylaxis were also found. ${ }^{7,8}$ In a study of 370 travelers at a Canadian travel clinic, children $<18$ years old accounted for $48 \%$ of the study subjects, of which $36 \%$ were adolescents. ${ }^{12}$ Adolescent travelers aged 12 17 years were more likely to travel for education/volunteer purposes or for vacation and less likely to travel for VFRs compared with young children. ${ }^{12}$ In this latter study, more

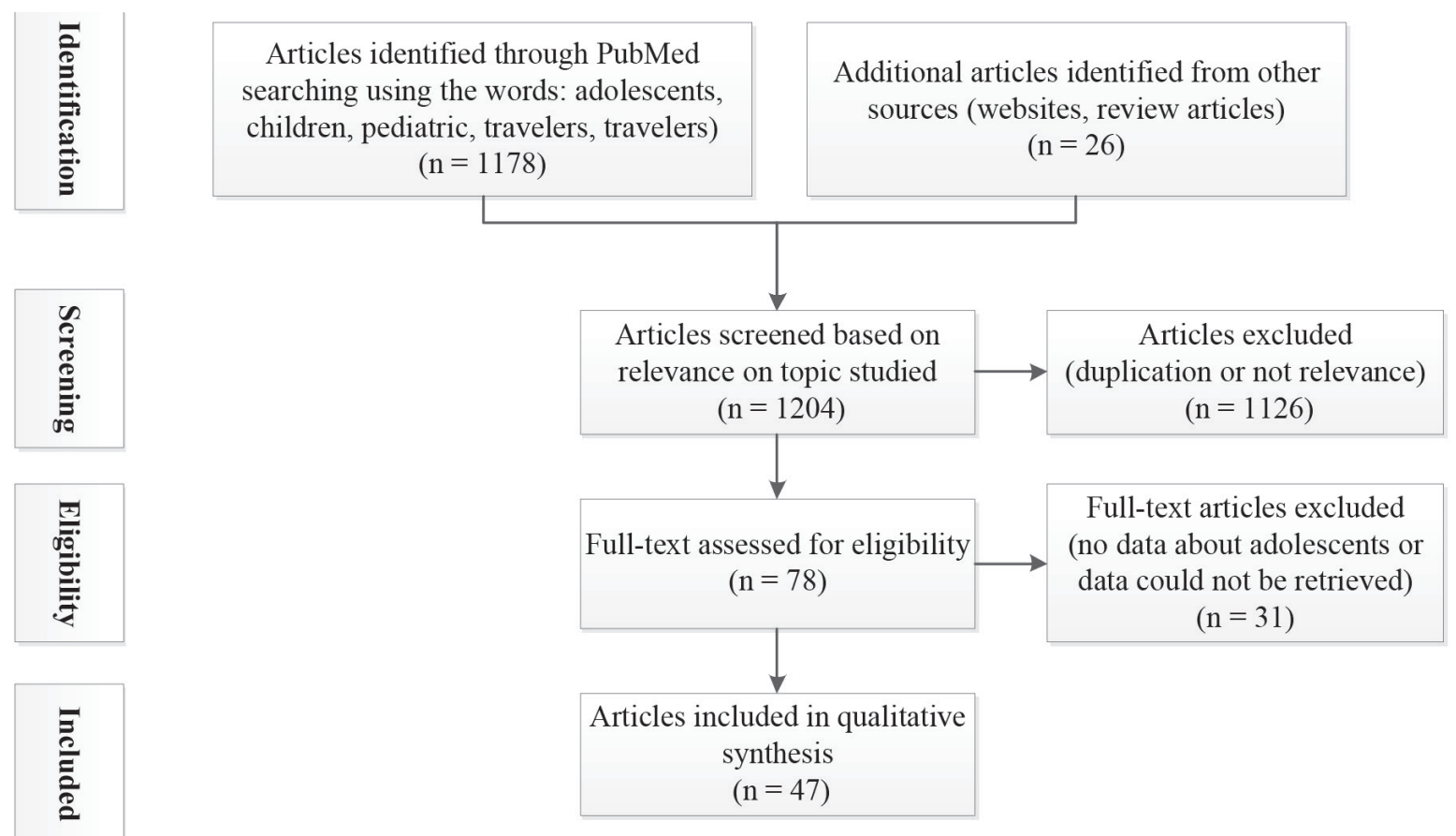

Figure 1. Flow Diagram of Literature Search. 
than one half of travelers visited the travel clinic within 4 weeks of their departure date. ${ }^{12}$ A 2008 Youth Styles survey among 1704 adolescents from the United States aged 9-18 years showed that $131(7.7 \%)$ of them had traveled in the past 12 months, mainly to Mexico (44.3\%), the Caribbean (42.4\%), and Central/South America (12\%); their main purpose was for vacation (81\%) followed by VFRs (21.7\%). ${ }^{17}$ Approximately one-fifth (18\%) of the adolescents traveled without parents (mean age: 15.5 years compared to 13.5 years for those traveling with their parents). Of those who travelled, only $16.7 \%$ sought pre-travel medical care. Among them, approximately two-thirds (63.7\%) reported that they did not receive any of the following: hepatitis A vaccine, typhoid fever vaccine, yellow fever vaccine, meningitis vaccine, malaria prophylaxis, or antidiarrhea prophylaxis. Males, older youths (14-18 compared with 9-13 years old), travelers and those who did not seek pre-travel medical care had higher mean sensation-seeking scores. ${ }^{17}$ A United States study of 1,731 travelers $<18$ years old showed that although adolescents 12-18 years accounted for 1,053 (61\%) travelers, they accounted for only 159 (26\%) of 610 VFRs. ${ }^{20}$ Similarly, adolescent travelers from Greece traveled less frequently to VFRs compared with younger children. ${ }^{78}$ These studies indicate gaps in pre-travel services and in the level of preparedness among adolescents traveling to high-risk destinations.

\section{Travel-Associated Morbidity}

International travelers often encounter illnesses or injuries. Data on travel-associated morbidity among adolescent travelers will assist healthcare professionals in improving their pre-travel services to them. In the United States 2008 Youth Styles survey of 1704 adolescents 9-18 years old, 20\% of travelers reported illness and injury during travel, including diarrhea, fever, cough/cold/pneumonia, and injury due to motorized vehicle accidents. ${ }^{17}$ In another 2-year survey of 784 travelers from the United States to international destinations, more than half of adolescent travelers 10-19 years of age reported that they encountered at least one health problem during their travel. ${ }^{19}$ A prospective study of reported morbidity following a travel from the Netherlands to Asia, Africa, or Latin America found that adolescent travelers 12-18 years of age had significantly higher ailment rates compared with younger children and their parents (11.2, 7.0, and 4.4 ailments per person-month of travel, respectively; $P$ value $<0.05){ }^{6}$ This is attributed to the fact that adolescents are less strictly supervised by their parents than younger children and may therefore engage more frequently in risk-seeking behavior. Overall, $85 \%$ of all children and $70 \%$ of all parents reported some kind of ailment during travel. ${ }^{6}$ In a Finnish study of ill or injured international travelers, infections (59.9\%) and injuries (14\%) were the most frequently diagnosed categories. ${ }^{10}$ In this series, young age (15-29 years) was a risk factor for hospitalization, along with male sex, vascular disease, and travel to sub-Saharan Africa, Australia, New Zealand, Oceania, or Asia. ${ }^{10}$ These studies indicate that adolescent travelers often face health problems while travelling abroad and have a different profile of morbidity than younger children or adults.

\section{Infectious Diseases}

Infectious diseases are a significant component of travelassociated morbidity during international travel. Data on travel-acquired infectious diseases among adolescent travelers is often fragmentary and sporadic with few exceptions. Hagmann et al analyzed the data from 1591 ill pediatric international travelers reported to the Geosentinel Surveillance Network during 1997-2007.5 Their main diagnoses were diarrheal disease (29\%), dermatologic disorders (25\%), systemic febrile illness (23\%), and respiratory disorders (11\%). There were 653 adolescents 12 17 years old in this cohort. ${ }^{5}$ Their main destinations were Asia, Latin America and sub-Saharan Africa (27\%, 26\% and $24 \%$, respectively), and $67 \%$ of them travelled for recreational purposes followed to VFRs or to participate in a mission/ volunteer (12\% each). Despite the fact that they traveled to high-risk destinations, only half of them (48\%) received pretravel counseling. ${ }^{5}$ In terms of morbidity, adolescent travelers had a higher proportionate morbidity rate for systemic febrile illnesses compared with younger children. Compared with shorter travels, long-term travels ( $>30$ days) also increased the odds of the diagnosis of systemic febrile illness. ${ }^{5}$ In another study of travel-associated illness in children from Switzerland during 2007-2008, the proportion of children with diarrheal disease, other gastrointestinal and genitourinary disease, injury, or musculoskeletal disease increased with increasing age, while the proportion with respiratory illness declined with increasing age. ${ }^{18}$ In conclusion, the published data also indicates a different spectrum of health problems among adolescent travelers.

There is very little published data about infectious-related morbidity among adolescent travelers by infectious syndrome. In a study of 890 children and adolescents presenting to the University of Munich outpatient travel clinic (Germany) during 1999-2009 after returning from Africa (46\%), Asia (35\%), or Latin America (19\%), the most common clinical syndromes were acute diarrhea (25\%), dermatologic disorders (21\%), febrile/systemic illnesses (20\%), and respiratory diseases $(8 \%){ }^{4}$ In this study, the highest risk for acquisition of any infectious disease was noted after a trip to Central, West, or East Africa (increased by 20.71-, 9.53- and 6.22-times, respectively), followed by a trip to South America (x1.94) or South/Southeast Asia (x1.57). Compared with the younger pediatric age groups, adolescents aged 15-19 years were more frequently involved in adventure travel and backpacking with low hygiene standards; they less frequently traveled to VFRs. ${ }^{4}$ In terms of diagnoses, dengue fever was significantly more common among adolescents 10-14 and $15-19$ years old (6.6\% and $2.4 \%$, respectively) compared with younger age groups $(0 \%$ and $1.3 \%$ in $0-4$ and $5-9$ years old, respectively) $(P$ value $<0.01)$. Similarly, mononucleosis was more frequently diagnosed in adolescents 10-14 and 15-19 years old (2.5\% and 3.9\%, respectively) than among younger children ( $0 \%$ and $0.6 \%$ in $0-4$ and 5-9 years old, respectively) $(P$ value $=0.02)$. In addition, adolescents $15-19$ years old more frequently presented with genitourinary disorders (urinary tract infection, vaginitis, herpes genitalis) compared with 
younger age groups $(4.6 \%$ compared with $0.6 \%$ in 0 - 4 -yearold travelers and $2.5 \%$ in 5-9-year-old and 10-14-yearold travelers; $P$ value $=0.07$ ). In contrast, acute diarrhea and dermatologic disorders were statistically significantly more common in young children. ${ }^{4}$ International travel also accounts for almost all cases of typhoid fever and more than $40 \%$ of hepatitis A cases in many developed countries, mainly in youth and persons $<35$ years. ${ }^{26,27}$ Published data showed a different spectrum of travel-acquired infectious diseases among adolescents.

Malaria is associated with a significant morbidity and occasionally mortality and high healthcare costs in the returning traveler. Children account for a considerable proportion of imported malaria in non-endemic developed countries and are at risk for severe and life-threatening complications, especially when infected with Plasmodium falciparum..$^{28}$ Children and adolescent VFRs are at increased risk for the acquisition of malaria. ${ }^{25}$

In a study of 17009 pediatric malaria cases imported in Australia, Japan, the United States, and eight European countries during 1992-2002, adolescents 15-17 years of age accounted for the largest overall percentage (3079 cases; $18.1 \%$ ), while in Australia and the Netherlands the 15-17-year-old group accounted for $30.3 \%$ and $27.4 \%$ of cases, respectively. ${ }^{21}$ Most cases (77\%) were imported from Africa, mainly from West Africa, and were caused by $P$. falciparum. ${ }^{21}$ Inadequate compliance of travelers with the appropriate preventive measures was a major issue. In the abovementioned study, only $17.5 \%$ of malaria cases had taken antimalarial prophylaxis. ${ }^{21}$ In another study of imported malaria among persons $<20$ years of age in Spain during 19902008, adolescents 15-19 years old accounted for 50 out of 174 cases; $88 \%$ of adolescents $15-19$ years were immigrants. ${ }^{22}$ In this study, traveling to VFRs and an age of 15-19 years were statistically significantly associated with imported malaria among immigrant residents (odds ratios [ORs] $=6.2$ and 3.7, respectively). ${ }^{22}$

Dengue and other vector-borne diseases are also serious infections for travelers to endemic areas. In a series of 8 cases of severe dengue in pediatric VFR travelers after a trip to the Caribbean, six were adolescents (median age: 13.6 years). ${ }^{15}$ Patients had a median stay at their destination of 32 days and presented because of an acute febrile illness within 11 days after they returned. ${ }^{15}$ In 2 adolescents the diagnosis of dengue hemorrhagic fever was established based on clinical and laboratory findings. ${ }^{15}$ Similarly, adolescents $10-19$ years old accounted for almost all cases of dengue fever diagnosed among children out of a total of 676 laboratory-confirmed dengue cases imported in Belgium over the period 20022013. ${ }^{16}$ From January to 15 July 2016, 625 Zika virus infection cases were reported in France including 15 (2\%) adolescents aged 10-19 years. ${ }^{14}$ Most of them (85\%) were imported from Martinique, French Guiana, and other French departments of the Americas. ${ }^{14}$ It is possible that adolescents were underrepresented in this series of laboratory-confirmed Zika infections, not because they were not infected, but rather because childbearing-age groups constitute the target groups for confirming a diagnosis in the frame of the teratogenic effects of the Zika virus.

Vaccine-preventable diseases also account for a significant portion of infectious-associated morbidity for unvaccinated travelers to endemic areas or areas with outbreaks. A telephone-based survey of 44 measles cases in Australia during 2013-2014 showed that adolescents contributed significantly to measles importation in this country. ${ }^{13}$ In particular, of the 44 measles cases including 9 (20.5\%) adolescents, 25 (56.8\%) had a history of travel abroad. ${ }^{13}$ Of them, only one (4\%) had received pre-travel advice. The main reasons for not seeking pre-travel advice were "no perceived risk of diseases" and "previous overseas travel without any problem". ${ }^{13}$ In another multi-center study, adolescents accounted for 4 (6\%) of 74 travel-acquired cases of pertussis. ${ }^{9}$

Sexually-transmitted infections (STIs) are also of concern for adolescent international travelers, since young age (15-25 years old) is a common risk factor for travel-acquired STIs. ${ }^{11}$ Although adolescents and young adults constitute $25 \%$ of the sexually active population, these age groups account for almost $50 \%$ of all new acquired STIs. ${ }^{23}$ This is explained by the increased likelihood among young people to engage in high-risk sexual behavior compared with older age groups, in the light of meeting new people and the willing for new experiences. ${ }^{11}$ Male sex, traveling to VFRs, not having a pretravel consultation, and a duration of travel $<30$ days are also independently associated with a diagnosis of STI among travelers. ${ }^{11}$ Additional risk factors for engaging in casual sex while traveling include paying for sex, multiple partners, casual sex or multiple partners at home, longer duration of stay, and use of alcohol or illicit drugs. ${ }^{11}$ It is estimated that only $50 \%$ of travelers use condoms during casual contact abroad. ${ }^{29}$ A broad spectrum of travel-acquired STIs has been noted, depending on destinations and travelers' demographic characteristics. Prevalence rates as high as $5.7 \%-17 \%$ for gonorrhea were noted in sub-Saharan Africa, followed by $0.1 \%-3.5 \%$ in Asia and Western Pacific. ${ }^{11}$ Transmission is facilitated by the fact that gonorrhea is mainly transmitted by asymptomatic carriers; the underreporting of cases also contributes to transmission. ${ }^{11}$ Chlamydiasis is diagnosed mainly among young sexually active women, particularly adolescents. ${ }^{24}$ Syphilis outbreaks have been reported following the importation of travel-acquired cases from developing countries, where seroprevalence rates range from 3.5\%-8\% in South/Southeast Asia, to 5\%-6\% in Latin America and 2.5\%-17\% in sub-Saharan Africa. ${ }^{11}$ Other STIs of importance for the traveler include chancroid (which is endemic in many developing countries), lymphogranuloma venereum, granuloma inguinale, trichomoniasis, genital herpes, genital warts, and human immunodeficiency virus (HIV) infection. The highest prevalence rates of HIV are noted in subSaharan Africa followed by Southeast Asia, while HIV/AIDS is emerging in post-Soviet countries. ${ }^{11}$ STIs are a significant cause of health problems among adolescents engaged in highrisk behavior, and appropriate recommendations should be offered.

\section{Vaccinations}

Vaccinations account for an important section of pre-travel 
services. Pre-travel counseling should be offered timely, and all recommended vaccinations should be completed one month before departure. Adolescents should be up-to-date with routine vaccinations, and pre-travel services offer an excellent opportunity for catch-up routine vaccinations. ${ }^{7,8}$ Vaccines that are specifically recommended in early adolescence include one booster dose of diphtheria-tetanusacellular pertussis-inactivated poliomyelitis (DTaP-IPV) vaccine and human papilloma virus (HPV) vaccine. Parents who refuse their children vaccinations because they rely on herd immunity in their country should be informed that herd immunity does not exist against tetanus or infectious diseases that are still endemic in destination countries (e.g., measles).

Following a risk-assessment based on the travelers' and travel characteristics, specific vaccines may be recommended. These include the typhoid, rabies, cholera, Japanese encephalitis, tick-borne encephalitis, yellow fever, hepatitis A vaccine, and the tetravalent meningococcal (A,C,W135,Y) vaccine. Influenza vaccination should also be considered based on season and travel destination.

\section{Antimalarial Prophylaxis in Adolescents}

Adolescents should be informed about the risk of malaria at their destination, malaria illness, risk factors and preventive measures. $^{30,31}$ A combination of preventive measures will provide the best protection. The insect repellent DEET $(N$, $N$,diethyl- $m$-toluamide or $N, N$-diethyl-3-methylbenzamide) is safe and effective and has been used for more than five decades. ${ }^{32}$ Herbal repellents containing citronella, eucalyptus, or other herbs are not as effective as DEET, and environmental insecticides offer limited protection. ${ }^{30,33}$ If sleeping outdoors or in unscreened accommodations, insecticide-treated mosquito nets should be used. Mosquito bed nets must be free of tears. ${ }^{31}$ Clothes and bed-nets are useful bite barriers during dusk and dawn. ${ }^{33,34}$ Insecticides can be impregnated into bednets, applied to clothes, or be sprayed. Their protection can last for several weeks, even if laundered. If more concentrated forms of insecticides are used, protection can last up to 12 months. ${ }^{35}$

The decision to provide antimalarial prophylaxis is based on travel characteristics and local resistance patterns. Mefloquine is effective and safe, however it is only available in tablet formulation. Side effects in prophylactic doses are usually similar to the effects in adults, however vomiting is more common in children. ${ }^{35}$ The combination of atovaquone and proguanil is also safe and effective in traveling adolescents, however, cost and daily compliance are important issues. ${ }^{34}$ Daily doxycycline is recommended for adolescents $>8$ years who are traveling to areas of mefloquine-resistant malaria or who are not able to take other products. Doxycycline is not recommended for children $<8$ years of age because of concerns in relation to the staining of growing teeth. Antifungal agents are recommended for adolescent girls taking doxycycline in case of symptomatic vaginal candidiasis. ${ }^{33,34}$

For adolescents traveling to chloroquine-resistant endemic areas, mefloquine atovaquone-proguanil, or doxycycline, is usually recommended, except in areas of Southeast Asia where mefloquine resistance occurs. For adolescents with normal G-6-PD activity, primaquine is another prophylactic option, although less effective. ${ }^{31,34}$ Chloroquine is another safe drug for malaria prophylaxis in adolescents and can be used for destinations where P. falciparum is still sensitive. Although the risk of retinopathy is low, periodic eye examinations are recommended for adolescents using chloroquine for $>5$ years. $^{34}$

All travelers, parents and adolescents, should be advised to seek immediate medical attention for prompt diagnosis and treatment if signs and symptoms of malaria occur either while abroad or up to a year after their return. ${ }^{31,34}$ Fever in travelers returning from the tropics should be considered to be malaria until proven otherwise. Suspected cases should be investigated urgently by blood films. ${ }^{31,34}$

\section{Accidents in Adolescent Travelers}

Traffic accidents, drowning, accidents related to waterrelated activities, and violence constitute the most common causes of injuries in travelers, including adolescents. Other causes of injuries include natural hazards during outdoor and wilderness activities. It is expected that the increasing popularity of eco-tourism and adventure travel will likely increase the number and diversity of accidents in remote locations, falls, burns, poisoning, drug overdose, suicide, civil unrest, and terrorism. ${ }^{36}$ Travelers are ten-times more likely to die from injury than from infection while abroad. ${ }^{37,38}$ Motor vehicle accidents are the leading cause of death among pediatric and adolescent international travelers, accounting for more than half of fatal events; drowning is the second most common cause of death. ${ }^{36-40}$ It has been estimated that United States pediatric travelers 0-14 years old are more than 2-times as likely to die from a motor vehicle accident and 3.7 times as likely to die as a result of drowning, compared with non-travelers. ${ }^{39}$ Families should be strongly advised to supervise their children around streets and roads. In developing countries, traffic rules may not be enforced. Travelers should "look both ways" before crossing streets in countries with driving habits different from their country of origin. ${ }^{33}$ Safety belts should always be used. ${ }^{41}$ Children should always be supervised near water, and an adult "buddy" should always be available in the water close to a child when playing in the water. ${ }^{42}$ Risk factors for boating injuries such as alcohol consumption by drivers and propellers left running while people are still swimming or climbing in or out of the boat should be avoided. Parents and adolescents planning to use a boat at their travel destination should be well informed about good boating safety practices. ${ }^{33}$

Visiting animals may be one of the pleasant recreation activities when traveling overseas; however, travelers should be aware of safety precautions around animals. Animal bites are relatively common in travelers, including adolescents. ${ }^{43}$ To avoid animal bites, travelers should avoid playing around unknown animals, and animals should always be viewed from a safe distance. Animal bites should be treated immediately by a health professional in view of injury, bacterial contamination, and rabies. International travelers to rabies-endemic regions, particularly to Asia and Africa, should be informed about the potential of rabies exposure and the efficacy and safety of pre- 


\section{Review Highlights}

What Is Already Known?

Adolescents increasingly travel to high-risk international destinations.

\section{What This Study Adds?}

Gaps in vaccinations, antimalarial prophylaxis, and pre-travel counseling for adolescents traveling to highrisk destinations were identified. The articles reviewed reported $50 \%-83 \%$ of adolescents failed to receive pretravel counseling. Adolescent travelers often have a different travel-associated morbidity related to their frequent engagement in high-risk behaviors. In some studies, adolescent travelers were reported more likely to become ill compared with young children and adults. The most common travel-related diseases were infections and injuries. Antimalarial prophylaxis was only taken by $17.5 \%$ of malaria cases in a large study. Pre-travel counseling for high-risk behavior of adolescents should be improved.

travel vaccination against rabies. ${ }^{33,43}$

Alcohol and Substance Use, Body Piercing and Tattoo Alcohol and substance use may represent a significant problem for adolescents during travel. In a recent study, two thirds of young holidaymakers, including adolescents, visiting Mediterranean destinations reported having been drunk on holiday, and over $10 \%$ using illicit drugs. Levels of drunkenness and drug use varied with nationality and holiday destinations. Using drugs other than just cannabis on holidays and frequent drunkenness were also predictors of unintentional injury. ${ }^{44}$ Drug use trends and attitudes in young travelers showed similar trends to "settled" adolescents, however, their level of health awareness and knowledge of drug services is poor; this may be related to the social isolation of young travelers which makes them vulnerable to drug use as a result of poor knowledge of service provision and literacy levels relating to drug education and treatment. ${ }^{45,46}$ During pre-travel consultations, adolescents and their parents/supervisors should be advised to be careful to avoid the unsafe use of alcohol and other illicit substances during foreign travel.

Body piercing and tattooing when the sterilization of needles between subjects is not performed on a routine basis or when a common source of tattoo dye is used for multiple recipients are well known sources of transmission of hepatitis B, hepatitis C, HIV and syphilis in highly endemic countries. ${ }^{11}$ Adolescents frequently engage in such activities. Therefore, piercing, tattooing, and acupuncture should be avoided in settings with low or unknown hygiene standards. ${ }^{47}$ The reuse of needles or syringes should be strictly not allowed.

\section{Additional Precautions}

Used properly, condoms offer protection against STIs during sexual activity, and adolescents should be advised for their consistent use. However, they should be advised that barriers do not offer $100 \%$ protection. Vaccination against hepatitis
B and HPV should be offered. ${ }^{11}$ Pregnancy issues should be discussed. Adolescents should be advised that monogamous sex with a stable, uninfected partner or sexual abstinence are the only ways to efficiently protect against STIs. Pre-travel counseling should offer the opportunity to discuss with adolescents sexual behavior and other high-risk behaviors in the absence of parents.

Adolescents with pre-existing medical conditions should be advised to get their medications for their entire trip before departure. Preventive measures for the prevention and management of travelers' diarrhea should also be discussed. All travelers should have a medical insurance for potential healthcare seeking, hospitalization, and medical transportation while abroad.

\section{Conclusion}

Very few studies present original data on adolescent international travelers. Adolescents increasingly travel abroad; however, inadequate pre-travel counseling, vaccinations, and antimalarial prophylaxis are common in this age group. In particular, most adolescent international travelers fail to receive pre-travel counseling. In addition, adolescents are frequently involved in high-risk behaviors during travel. Adolescents often demonstrate a different travel-associated morbidity compared with younger children and adults. Pre-travel counseling about vaccinations, antimalarial prophylaxis, and the prevention of high-risk behavior for adolescents planning to travel abroad should be improved. Communication strategies to access adolescent travelers and their parents should be developed.

\section{Authors' Contributions}

HCM and AP significantly contributed towards this study.

\section{Conflict of Interest Disclosures}

The authors state they have no conflicts of interest to declare.

\section{Ethical Approval}

Not applicable.

\section{Funding/Support}

No funds were received for the study.

\section{References}

1. Annual report 2016. World Tourism Organization Website. http:// cf.cdn.unwto.org/sites/all/files/pdf/annual_report_2016_web_0. pdf. Accessed March 24, 2018.

2. Weinberg N, Weinberg MS, Maloney SA. International travel with infants and children. In: Centers for Disease Control and Prevention. Health information for international travel (Yellow Book). 2018. https://wwwnc.cdc.gov/travel/yellowbook/2018/ international-travel-with-infants-children/traveling-safely-withinfants-children. Accessed: March 24, 2018.

3. D'Anjou AM. Youth tourism in Canada: a situational analysis of an overlooked market. Ontario, Canada: Youth Tourism Consortium of Canada; 2004.

4. Herbinger KH, Drerup L, Alberer M, Nothdurft HD, Sonnenburg F, Loscher T. Spectrum of imported infectious diseases among children and adolescents returning from the tropics and subtropics. J Travel Med. 2012;19(3):150-157. doi:10.1111/ 
j.1708-8305.2011.00589.x.

5. Hagmann S, Neugebauer R, Schwartz E, et al. Illness in children after international travel: analysis from the GeoSentinel Surveillance Network. Pediatrics. 2010;125(5):e1072-1080. doi:10.1542/peds.2009-1951.

6. van Rijn SF, Driessen G, Overbosch D, van Genderen PJ. Travelrelated morbidity in children: a prospective observational study. J Travel Med. 2012;19(3):144-149. doi:10.1111/j.17088305.2011.00551.x.

7. Maltezou HC, Pavli A, Theodoridou K, et al. Preparedness of adolescents departing from Athens International Airport to Africa or Asia: A five-year airport-based prospective study. Travel Med Infect Dis. 2018;21:69-73. doi:10.1016/j.tmaid.2017.07.011.

8. Maltezou HC, Pavli A, Theodoridou K, et al. Vaccinations and Malaria Chemoprophylaxis of Adolescents Traveling From Greece to International Destinations: A Nine-Year Prospective Study. Pediatr Infect Dis J. 2018;37(5):e132-e135. doi:10.1097/ inf.0000000000001782.

9. Barbosa F, Barnett ED, Gautret P, et al. Bordetella pertussis infections in travelers: data from the GeoSentinel global network. J Travel Med. 2017;24(3). doi:10.1093/jtm/taw094.

10. Siikamaki H, Kivela P, Fotopoulos M, Ollgren J, Kantele A. Illness and injury of travellers abroad: Finnish nationwide data from 2010 to 2012, with incidences in various regions of the world. Euro Surveill. 2015;20(19):15-26. doi:10.2807/1560-7917. ES2015.20.19.21128.

11. Korzeniewski K, Juszczak D. Travel-related sexually transmitted infections. Int Marit Health. 2015;66(4):238-246. doi:10.5603/ imh.2015.0045.

12. Ma XW, Pell LG, Akseer N, et al. Characteristics and pre-travel preparation of travelers at a Canadian pediatric tertiary care travel clinic: A retrospective analysis. Travel Med Infect Dis. 2016;14(2):148-154. doi:10.1016/j.tmaid.2015.11.012.

13. MacIntyre CR, Karki S, Sheikh M, Zwar N, Heywood AE. The role of travel in measles outbreaks in Australia - An enhanced surveillance study. Vaccine. 2016;34(37):4386-4391. doi:10.1016/j. vaccine.2016.07.023.

14. Septfons A, Leparc-Goffart I, Couturier E, et al. Travel-associated and autochthonous Zika virus infection in mainland France, 1 January to 15 July 2016. Euro Surveill. 2016;21(32). doi:10.2807/15607917.es.2016.21.32.30315

15. Krishnan N, Purswani M, Hagmann S. Severe dengue virus infection in pediatric travelers visiting friends and relatives after travel to the Caribbean. Am J Trop Med Hyg. 2012;86(3):474-476. doi:10.4269/ajtmh.2012.11-0411.

16. Verschueren J, Cnops L, van Esbroeck M. Twelve years of dengue surveillance in Belgian travellers and significant increases in the number of cases in 2010 and 2013. Clin Microbiol Infect. 2015;21(9):867-872. doi:10.1016/j.cmi.2015.05.029.

17. Han P, Balaban V, Marano C. Travel characteristics and risktaking attitudes in youths traveling to nonindustrialized countries. J Travel Med. 2010;17(5):316-321. doi:10.1111/j.17088305.2010.00444.x

18. Hunziker T, Berger C, Staubli G, et al. Profile of travelassociated illness in children, Zurich, Switzerland. J Travel Med. 2012;19(3):158-162. doi:10.1111/j.1708-8305.2012.00611.x.

19. Hill DR. Health problems in a large cohort of Americans traveling to developing countries. J Travel Med. 2000;7(5):259-266. doi:10.2310/7060.2000.00075.

20. Han P, Yanni E, Jentes ES, et al. Health challenges of young travelers visiting friends and relatives compared with those traveling for other purposes. Pediatr Infect Dis J. 2012;31(9):915919. doi:10.1097/INF.0b013e318259efbe.

21. Stager K, Legros F, Krause G, et al. Imported malaria in children in industrialized countries, 1992-2002. Emerg Infect Dis. 2009;15(2):185-191. doi:10.3201/eid1502.080712.

22. Garcia-Villarrubia M, Millet JP, de Olalla PG, et al. Epidemiology of imported malaria among children and young adults in Barcelona (1990-2008). Malar J. 2011;10:347. doi:10.1186/1475-2875-10347.

23. Da Ros CT, Schmitt Cda S. Global epidemiology of sexually transmitted diseases. Asian J Androl. 2008;10(1):110-114. doi:10.1111/j.1745-7262.2008.00367.x.

24. Wilson JS, Honey E, Templeton A, Paavonen J, Mardh PA, StrayPedersen B. A systematic review of the prevalence of Chlamydia trachomatis among European women. Hum Reprod Update. 2002;8(4):385-394. doi:10.1093/humupd/8.4.385.

25. Barnett ED, MacPherson DW, Stauffer WM, et al. The visiting friends or relatives traveler in the 21st century: time for a new definition. J Travel Med. 2010;17(3):163-170. doi:10.1111/j.17088305.2010.00411.x.

26. Klevens RM, Miller JT, Iqbal K, et al. The evolving epidemiology of hepatitis $\mathrm{a}$ in the United States: incidence and molecular epidemiology from population-based surveillance, 2005-2007. Arch Intern Med. 2010;170(20):1811-1818. doi:10.1001/ archinternmed.2010.401.

27. Provost S, Gagnon S, Lonergan G, Bui YG, Labbe AC. Hepatitis A, typhoid and malaria among travelers--surveillance data from Quebec (Canada). J Travel Med. 2006;13(4):219-226. doi:10.1111/ j.1708-8305.2006.00031.x.

28. Angelo KM, Libman M, Caumes E, et al. Malaria after international travel: a GeoSentinel analysis, 2003-2016. Malar J. 2017;16(1):293. doi:10.1186/s12936-017-1936-3.

29. Croughs M, Van Gompel A, de Boer E, Van Den Ende J. Sexual risk behavior of travelers who consulted a pretravel clinic. J Travel Med. 2008;15(1):6-12. doi:10.1111/j.1708-8305.2007.00160.x.

30. Fischer PR, Bialek R. Prevention of malaria in children. Clin Infect Dis. 2002;34(4):493-498. doi:10.1086/338257.

31. Guidelines for malaria prevention in travelers from the UK 2017. Public Health England website. https://www.gov.uk/government/ uploads/system/uploads/attachment_data/file/660051/ Guidelines_for_malaria_prevention_in_travellers_from_the_ UK_2017.pdf. Accessed March 24,2018.

32. Qiu H, Jun HW, McCall JW. Pharmacokinetics, formulation, and safety of insect repellent N,N-diethyl-3-methylbenzamide (deet): a review. J Am Mosq Control Assoc. 1998;14(1):12-27.

33. Summer AP, Fischer PR. The pediatric and adolescent traveler. In: Keystone J, et al, eds. Travel Medicine. United States: Elsevier; 2013:231-240.

34. International travel and health. Malaria. World Health Organization website. http://www.who.int/ith/2017-ith-chapter7. pdf?ua=1. Accessed March 24, 2018.

35. Schlagenhauf $P$, Adamcova M, Regep L, Schaerer MT, Bansod S, Rhein HG. Use of mefloquine in children - a review of dosage, pharmacokinetics and tolerability data. Malar J. 2011;10:292. doi:10.1186/1475-2875-10-292.

36. Hargarten SW, Guler Gursu K. Travel-related injuries, epidemiology, and prevention. In: DuPont HL, Steffen R, eds. Textbook of Travel Medicine and Health. Ontario: Hamilton; 1997:258-261.

37. Hargarten SW, Baker TD, Guptill K. Overseas fatalities of United States citizen travelers: an analysis of deaths related to international travel. Ann Emerg Med. 1991;20(6):622-626. doi:10.1016/S01960644(05)82379-0.

38. Stewart BT, Yankson IK, Afukaar F, Medina MC, Cuong PV, Mock C. Road Traffic and Other Unintentional Injuries Among Travelers to Developing Countries. Med Clin North Am. 2016;100(2):331343. doi:10.1016/j.mcna.2015.07.011.

39. Guse CE, Cortes LM, Hargarten SW, Hennes HM. Fatal injuries of US citizens abroad. J Travel Med. 2007;14(5):279-287. doi:10.1111/j.1708-8305.2007.00133.x.

40. Wallace D, Sleet D. Non-infectious risks during travel. In: Arguin PM, Kozarsky PE, Reed C, eds. CDC health information for international travel. Atlanta: US Department of Health and Human Services; 2008 
41. Durbin DR. Child passenger safety. Pediatrics. 2011;127(4):e10501066.doi:10.1542/peds.2011-0215.

42. Orlowski JP, Szpilman D. Drowning. Rescue, resuscitation, and reanimation. Pediatr Clin North Am. 2001;48(3):627-646. doi:10.1016/S0031-3955(05)70331-X.

43. Gautret P, Harvey K, Pandey P, et al. Animal-associated exposure to rabies virus among travelers, 1997-2012. Emerg Infect Dis. 2015;21(4):569-577. doi:10.3201/eid2104.141479.

44. Hughes $\mathrm{K}$, Bellis MA, Calafat $\mathrm{A}$, et al. Substance use, violence, and unintentional injury in young holidaymakers visiting
Mediterranean destinations. J Travel Med. 2011;18(2):80-89. doi:10.1111/j.1708-8305.2010.00489.x.

45. Van Hout MC, Connor S. The normalisation of substance abuse among young travellers in Ireland: implications for practice. J Ethn Subst Abuse. 2008;7(1):5-21. doi:10.1080/15332640802081687.

46. Nield LS. Health implications of adolescent travel. Pediatr Ann. 2011;40(7):358-361. doi:10.3928/00904481-20110615-08.

47. Streeton CL, Zwar N. Risk of exposure to hepatitis B and other bloodborne viruses among Australians who travel abroad. J Travel Med. 2006;13(6):345-350.doi:10.1111/j.1708-8305.2006.00069.x. 